\title{
Mild Steel Corrosion Mitigation in Sulphuric Acid via Benign Isolated Phytochemicals from Viscum album
}

\author{
N. E. Nya ${ }^{1}$, A. I. Ikeuba1 ${ }^{1}$, P. C. Okafor ${ }^{1 *}$, B. U. Ugi ${ }^{1}$, V. M. Bassey ${ }^{1}$, A. I. Obike ${ }^{2}$ \\ ${ }^{1}$ Corrosion and Electrochemistry Research Group, Department of Pure and Applied Chemistry, University of Calabar, Calabar, \\ Nigeria \\ ${ }^{2}$ Department of Chemistry, Abia State University, Uturu, Nigeria \\ Email: *pcokafor@unical.edu.ng, *pcokafor@gmail.com
}

How to cite this paper: Nya, N.E., Ikeuba, A.I., Okafor, P.C., Ugi, B.U., Bassey, V.M. and Obike, A.I. (2018) Mild Steel Corrosion Mitigation in Sulphuric Acid via Benign Isolated Phytochemicals from Viscum album. Journal of Materials Science and Chemical Engineering, 6, 132-146.

https://doi.org/10.4236/msce.2018.64014

Received: March 23, 2018

Accepted: April 25, 2018

Published: April 28, 2018

Copyright $\odot 2018$ by authors and Scientific Research Publishing Inc. This work is licensed under the Creative Commons Attribution International License (CC BY 4.0).

http://creativecommons.org/licenses/by/4.0/

\begin{abstract}
We present the evaluation of four Eco-friendly corrosion inhibitors for the corrosion mitigation of mild steel in acid media. The corrosion inhibition of mild steel by ethanol extracts from Viscum album (EEVA) and some of its isolated phytochemical components; phytates extract (PEVA), saponins extract (SEVA), and flavonoids extracts (FEVA) have been studied using gravimetric and gasometric techniques. The results of the study reveal that these ecofriendly and benign extracts function as good inhibitors for mild steel corrosion in sulphuric acid. Inhibition efficiency of the extracts increases with inhibitor concentration and temperature rise. The trend of inhibition efficiency in lower inhibitor concentration is EEVA $>$ PEVA $>$ SEVA $>$ FEVA and at higher concentration, the order was SEVA $>$ PEVA $>$ EEVA $>$ FEVA. The presence of the plant extracts decreases the corrosion activation energy in the solution which indicates chemical adsorption mechanism. The adsorption of the components of the extracts is consistent with Temkin isotherm. The interaction between the isolated extracts is synergistic at lower inhibitor concentration and antagonistic at higher concentrations. The $\mathrm{K}_{\mathrm{ads}}$ values for PEVA and SEVA are higher than those of EEVA and FEVA. This implies that PEVA and SEVA are more efficiently adsorbed on the mild steel surface.
\end{abstract}

\section{Keywords}

Acid Corrosion, Mild Steel, Viscum album, Corrosion Inhibition, Phytochemicals

\section{Introduction}

Mild steel has been extensively used under different conditions in chemical and 
allied industries in handling alkaline, acid and salt solutions. Sulphate ions in aqueous media are particularly aggressive and accelerate corrosion. The known hazardous effects of most synthetic corrosion inhibitors are the motivation for the use of some natural products. Green corrosion inhibitors are ecofriendly and biodegradable and do not contain heavy metals or other toxic compounds. Inhibitors in this class are those that are environmentally friendly and are obtained from natural products such as plant extracts [1]. The use of natural products as corrosion inhibitors has been widely reported by several authors. The extracts from leaves, seeds, bark, roots and fruits of plants have been reported to inhibit metallic corrosion in acidic media [2]-[11]. Viscum album (Mistletoe) is a common bushy plant of the family Loranthaceae, which grows as an epiphyte on the branches of deciduous trees. The plant is widely distributed in tropical and subtropical Africa, in Asia and in Europe [12]. The plant is used in the treatment of nervous complaints, bleeding and tumors [12] [13]. The extracts from the leaves stimulate insulin secretion from pancreas cells and help in the treatment of arthritis [14] [15] [16] [17] [18]. This medicinal plant is believed to be rich in nitrogen, sulphuric and oxygen containing organic compounds thus could exhibit a very strong inhibitive effect on corrosion of steel. These compounds provide good adsorption sites unto the metal surface via the residual lone pair of electrons on the hetero atoms present in their molecular structure.

Over the past decades, researchers have concentrated on the use of different parts of plant extracts as corrosion inhibitors in various media. The inhibitive effect has always been attributed to active phytochemicals (glycosides, phytates, saponins, flavonoids and tannins amongst others) in the extracts [18]-[24]. This research assertion is rather general as there is no experimental evidence indicating the phytochemical that contributes majorly to the inhibitory properties of the extracts. Also little is known about the synergistic and antagonistic effects of these phytochemicals in the extract. This work presents results of experiments designed to investigate the corrosion inhibition performance of the isolated phytochemicals in Viscum album leaves on mild steel corrosion in $\mathrm{H}_{2} \mathrm{SO}_{4}$ solutions using gasometric and weight loss techniques. This is in order to ascertain the major active component responsible for the corrosion inhibition and to gain more understanding of the synergistic/antagonistic relationships between the extracts. For the purpose of this study, the phytochemicals that were isolated are phythates, saponins and flavonoids.

\section{Experimental}

\subsection{Materials Preparation}

The mild steel sheet used for the study were of composition (wt \%) Mn (0.64), $\mathrm{P}$ (0.06), C (0.19), S (0.05), Ni (0.09), Cr (0.08), Mo (0.02), Cu (0.27), Si (0.26) and the rest Fe. The sheet was cut into coupons of dimension $2 \times 0.08 \times 5 \mathrm{~cm}$ and $4 \times$ $0.08 \times 5$ for the hydrogen evolution and weight loss measurements. Before measurements the mild steel coupons were mechanically polished with series of 
emery paper of up to 400 grits, degreased with absolute ethanol, dried in acetone and preserved in desiccators. Distilled water was used to prepare all experimental solutions. All other chemicals used were of Analar grade and all weighing was done with Mettler P 1210 digital analytical balance.

\subsection{Preparation of Plant Extracts}

The required plant parts Viscum album (Mistletoe) was collected from a local bush in Ikot Ekpene, Akwa Ibom State, Nigeria. These were cut into small chips and dried in an N53C-Genlab laboratory oven at $323 \mathrm{~K}$ and ground into powder form. $80 \mathrm{~g}$ of the powder was extracted continually with $250 \mathrm{~cm}^{3}$ of absolute ethanol in a soxhlet extractor for 24 hours. The extracted jell was heated in a water bath (at $333 \mathrm{~K}$ ) until most of the ethanol evaporated. $10 \mathrm{~g}$ of the ethanol extract was dissolved in 1 liter of $5.0 \mathrm{M} \mathrm{H}_{2} \mathrm{SO}_{4}$ solution. The resultant solution was kept for 24 hours, filtered and stored. From the stock solution (10.0 $\mathrm{g} / \mathrm{L}$ ), inhibitor test solutions were prepared at concentrations of $0.5,1.0,2.5,4.0$, 5.0 and $7.5 \mathrm{~g} / \mathrm{L}$. Phytochemical screening was carried out on the ethanol extracts of Viscum album following the methods previously described by [16] and Trease \& Evans [17]. The plant extracts were screened for alkaloids, saponins, tannins, flavonoids, phytates, phenols, oxalate and glycosides. The same procedure was repeated to obtain various concentrations of PEVA, SEVA and FEVA. Gasometric and weight loss experiments were then carried out using different concentrations of the extracts at different temperatures.

\subsection{Hydrogen Evolution Technique}

Gasometric assembly was used for the measurement of hydrogen gas evolution from corrosion reaction. The assembly was coupled and the connections were greased to avoid the escape of the gas. $100 \mathrm{~cm}^{3}$ of the corrodent $\left(5.0 \mathrm{M} \mathrm{H}_{2} \mathrm{SO}_{4}\right.$ solution) was introduced into the reaction chamber connected to a burette through a delivery tube. A sample of the polished mild steel coupon was dropped into the solution and the reaction chamber quickly closed to prevent any escape of hydrogen. The volume of the hydrogen gas evolved from the corrosion reaction was monitored by the depression $\left(\right.$ in $\mathrm{cm}^{3}$ ) in the paraffin oil level. This depression in the paraffin oil level was recorded every minute for 60 minutes ( 1 hour). The same experiment was repeated in the presence of $0.5,1.0$, 2.5, 4.0, 5.0, 7.5 and $10.0 \mathrm{~g} / \mathrm{L}$ ethanol extracts of Viscum album (EEVA) at $303 \mathrm{~K}$. Also the experiments were carried out with $2.5 \mathrm{~g} / \mathrm{L}$ EEVA at 313,323 and $333 \pm$ $2 \mathrm{~K}$. The same experiment was repeated in the presence of different concentrations $(0.5,1.0$ and $2.5 \mathrm{~g} / \mathrm{L})$ of SEVA, FEVA and PEVA at $303 \mathrm{~K}$. Then also, the experiments were repeated with $2.5 \mathrm{~g} / \mathrm{L}$ of each extract at 313,323 and $333 \pm 2 \mathrm{~K}$.

\subsection{Weight Loss Technique}

In the weight loss experiment, a weighed mild steel coupon was suspended in a beaker containing $100 \mathrm{~cm}^{3}$ of $5.0 \mathrm{M} \mathrm{H}_{2} \mathrm{SO}_{4}$ solution with the aid of glass rod and 
hook at room temperature. The mild steel coupon was completely immersed in the solution and after 1 hour the mild steel coupon was retrieved, washed, scrubbed with bristle brush by immersing it in $20 \% \mathrm{NaOH}$ containing $20 \mathrm{~g}$ of zinc-dust. After washing, the mild steel coupon was rinsed with absolute ethanol, dipped in acetone, air dried, re-weighed and re-immersed in the corrodent. The weight loss of the mild steel coupon was evaluated in grams as the difference between the initial and final weight of the coupon. This process was repeated progressively for 6 hours. The same experimental procedure was carried out in the presence of ethanol extracts of Viscum album using concentrations of 0.5 , 1.0, 2.5, 4.0, 5.0, 7.5 and 10.0 g/L. Experiments were carried out on mild steel coupons at room temperature $303 \mathrm{~K}$ only for the weight loss study.

\section{Results and Discussion}

\subsection{Phytochemical Screening Results}

Phytochemical screening was carried out on the ethanol extracts of Viscum album. The results obtained are shown in Table 1 and this indicates that the plant extracts contain glycosides, phytates, saponins, flavonoids and tannins. These compounds are heterogeneous organic compounds containing nitrogen, oxygen, sulphur and/or aromatic ring in the molecular structures. Organic heterogeneous compounds containing these elements have been reported to be efficient corrosion inhibitors [19] [24]. Thus, in the systems studied, these compounds are believed to contribute significantly to the inhibition of the corrosion reaction of the mild steel in acid media.

\subsection{Weight Loss}

The variation of the weight loss for mild steel coupons with immersion time in $5.0 \mathrm{M} \mathrm{H}_{2} \mathrm{SO}_{4}$ solutions in the absence and presence of EEVA at $303 \mathrm{~K}$ is shown in Table 2. From the results, it is observed that weight loss increases with time but decrease with increase in the concentration of the extracts. This behavior reflects the inhibitory effect of the extract toward the acid corrosion of the steel.

Table 1. Phytochemical screening of Viscum album.

\begin{tabular}{ccc}
\hline Phytochemicals & Test & Concentration/(\%) \\
\hline Alkaloids & - & $\mathrm{ND}$ \\
Oxalate & - & $\mathrm{ND}$ \\
Tannins & + & $1.44 \%$ \\
Saponins & + & 14.4 \\
Flavonoids & ++ & 14.0 \\
Phenol & - & $\mathrm{ND}$ \\
Phytates & ++ & 12.00 \\
Glycosides & ++ & 18.43 \\
\hline
\end{tabular}

Notes: +; moderately present in the extracts, ++; highly present, -; absent in the extract and ND, not determined. 
Table 2. Weight loss of mild steel in the presence and absence (blank) of EEVA in $5.0 \mathrm{M}$ $\mathrm{H}_{2} \mathrm{SO}_{4}$ at $303 \mathrm{~K}$.

\begin{tabular}{ccccccccc}
\hline \multicolumn{7}{c}{ Weight loss/(mg/cm $\left.{ }^{3}\right)$} \\
\hline Time/(hours) & Blank & $\mathbf{0 . 5} \mathrm{g} / \mathrm{L}$ & $\mathbf{1 . 0} \mathrm{g} / \mathrm{L}$ & $\mathbf{2 . 5} \mathrm{g} / \mathrm{L}$ & $\mathbf{4 . 0} \mathrm{g} / \mathrm{L}$ & $\mathbf{5 . 0} \mathrm{g} / \mathrm{L}$ & $\mathbf{7 . 5} \mathrm{g} / \mathrm{L}$ & $10.0 \mathrm{~g} / \mathrm{L}$ \\
\hline 1 & 0.272 & 0.202 & 0.167 & 0.124 & 0.091 & 0.084 & 0.063 & 0.011 \\
2 & 0.522 & 0.372 & 0.385 & 0.186 & 0.133 & 0.105 & 0.091 & 0.072 \\
3 & 0.903 & 0.653 & 0.564 & 0.242 & 0.172 & 0.143 & 0.104 & 0.083 \\
4 & 1.336 & 0.950 & 0.829 & 0.340 & 0.222 & 0.209 & 0.131 & 0.092 \\
5 & 1.817 & 1.303 & 1.095 & 0.443 & 0.276 & 0.221 & 0.143 & 0.103 \\
6 & 2.306 & 1.684 & 1.397 & 0.595 & 0.337 & 0.260 & 0.170 & 0.116 \\
\hline
\end{tabular}

The rates of corrosion (in $\mathrm{mg} \mathrm{cm}{ }^{-2} \cdot \mathrm{hr}^{-1}$ ) of the mild steel in the acid medium in the absence and presence of the plant extracts are presented in Table 3. It is clearly seen that the corrosion rate decreases with increase in the inhibitor concentration, indicating that the extent of inhibition is dependent on the amount of extract present. From the corrosion rate values, the inhibition efficiency (\%I) was determined using Equation (1).

$$
\% I=\frac{\left(C R_{\text {blank }}-C R_{\text {inh }}\right) \times 100}{C R_{\text {blank }}}
$$

where $C R_{\text {blank }}$ and $C R_{\text {inh }}$ are the corrosion rates in the absence and presence of the plant extracts. The results obtained are given in Table 3. It is observed that the inhibition efficiency increases as the added inhibitor concentrations are increased. This suggests that the phytochemical components of the extracts are adsorbed onto the mild steel surface resulting in the blocking of the reaction sites, thus protecting the mild steel surface from the attack of the corrosion active ions in the acid medium.

\subsection{Hydrogen Evolution}

The acid corrosion of mild steel is characterized by evolution of hydrogen and the rate of corrosion is proportional to the amount of hydrogen evolved [5] [7], thus the volume of hydrogen evolved $\left(V_{H}\right)$ during the corrosion of mild steel in $5.0 \mathrm{M} \mathrm{H}_{2} \mathrm{SO}_{4}$ solutions in the absence and presence of the ethanol extracts from Viscum album at $303 \mathrm{~K}$ as a function of time is depicted in Figure 1. The presence of the extract decreases the volume of hydrogen evolved during the corrosion reaction compared to the blank system. Also, similar trends were obtained at $313 \mathrm{~K}, 323 \mathrm{~K}$ and $333 \mathrm{~K}$ during the corrosion reaction for the extract of Viscum album with a concentration of $0.5,1.0,2.5$, and $5.0 \mathrm{~g} / \mathrm{L}$. The rate of hydrogen evolved was deduced from the slopes of the plots in Figure 1 and that for the elevated temperatures [18] and presented in Table 4. It is seen that the rate of hydrogen evolution decreases with increase in the extract concentrations and temperature. From the rate of hydrogen evolution, the inhibition efficiencies were determined using Equation (2). The results obtained are shown in Table 4 at $303 \mathrm{~K}$ and Table 5 at $(313,323$ and $333 \mathrm{~K})$. The inhibition efficiency was 
Table 3. Corrosion rate $(C R)$, Surface coverage $(\theta)$ and inhibition efficiency (\%) for mild steel in the presence and absence of EEVA in 5.0 $\mathrm{M} \mathrm{H}_{2} \mathrm{SO}_{4}$ at $303 \mathrm{~K}$.

\begin{tabular}{cccc}
\hline $\begin{array}{c}\text { Concentration } \\
(\mathrm{g} / \mathrm{L})\end{array}$ & $\begin{array}{c}\text { Corrosion rate } \\
\left(\mathrm{mg} / \mathrm{cm}^{2} / \mathrm{hr}\right)\end{array}$ & $\begin{array}{c}\text { Surface coverage } \\
(\theta)\end{array}$ & $\begin{array}{c}\text { Inhibition efficiency } \\
(\%)\end{array}$ \\
\hline Blank & 0.0100 & 0.28 & 28 \\
0.5 & 0.0072 & 0.41 & 41 \\
1.0 & 0.0059 & 0.78 & 78 \\
2.5 & 0.0022 & 0.88 & 88 \\
4.0 & 0.0012 & 0.91 & 91 \\
5.0 & 0.0009 & 0.95 & 95 \\
7.5 & 0.0005 & 0.96 & 96 \\
10.0 & 0.0004 & 1.00 & 99.99 \\
\hline
\end{tabular}

Table 4. Calculated values of the rate of hydrogen evolution $\left(R_{H}\right)$, surface coverage $(\theta)$ and inhibition efficiency (\%I) for mild in $5.0 \mathrm{M} \mathrm{H}_{2} \mathrm{SO}_{4}$ solution in the absence (blank) and presence of EEVA at 303.

\begin{tabular}{cccc}
\hline Concentration $(\mathrm{g} / \mathrm{L})$ & $\boldsymbol{R}_{H} /(\mathrm{cm} / \mathrm{min})$ & $\theta$ & $\boldsymbol{I}$ \\
\hline Blank & 0.0346 & - & - \\
0.5 & 0.0278 & 0.196 & 19.7 \\
1.0 & 0.0191 & 0.447 & 44.8 \\
2.5 & 0.0118 & 0.658 & 65.9 \\
4.0 & 0.0091 & 0.736 & 73.7 \\
5.0 & 0.0073 & 0.789 & 78.9 \\
7.5 & 0.0047 & 0.864 & 86.4 \\
10.0 & 0.0044 & 0.872 & 87.3 \\
\hline
\end{tabular}

Table 5. Calculated values of the rate of hydrogen evolution $\left(R_{H}\right)$, surface coverage $(\theta)$ and inhibition efficiency (\%I) for mild steel in $5.0 \mathrm{M} \mathrm{H}_{2} \mathrm{SO}_{4}$ solution containing, EEVA at 313,323 and $333 \mathrm{~K}$.

\begin{tabular}{cccccccccc}
\hline Conc. & \multicolumn{3}{c}{$R_{H} /(\mathrm{cm} / \mathrm{min})$} & \multicolumn{3}{c}{$\% I$} \\
\hline g/L & $313 \mathrm{~K}$ & $323 \mathrm{~K}$ & $333 \mathrm{~K}$ & $313 \mathrm{~K}$ & $323 \mathrm{~K}$ & $333 \mathrm{~K}$ & $313 \mathrm{~K}$ & $323 \mathrm{~K}$ & $333 \mathrm{~K}$ \\
\hline Blank & 0.1209 & 0.2397 & 0.3297 & - & - & - & - & - & - \\
0.5 & 0.0633 & 0.1147 & 0.1227 & 0.476 & 0.521 & 0.627 & 47.6 & 52.1 & 62.8 \\
1.0 & 0.0375 & 0.0695 & 0.0900 & 0.689 & 0.710 & 0.727 & 68.9 & 71.0 & 72.7 \\
2.5 & 0.0135 & 0.0229 & 0.0269 & 0.888 & 0.904 & 0.918 & 88.8 & 90.4 & 91.8 \\
\hline
\end{tabular}

observed to increase with an increase in the extracts concentration and temperature (Table 5). This observation however, suggests a chemical interaction between the metal surface and the phyto chemical components of EEVA.

$$
\% I=\frac{\left(R_{H B}-R_{H I}\right) \times 100}{R_{H B}}
$$

where $R_{H B}$ and $R_{H I}$ are the rates of hydrogen evolution in the absence and presence 


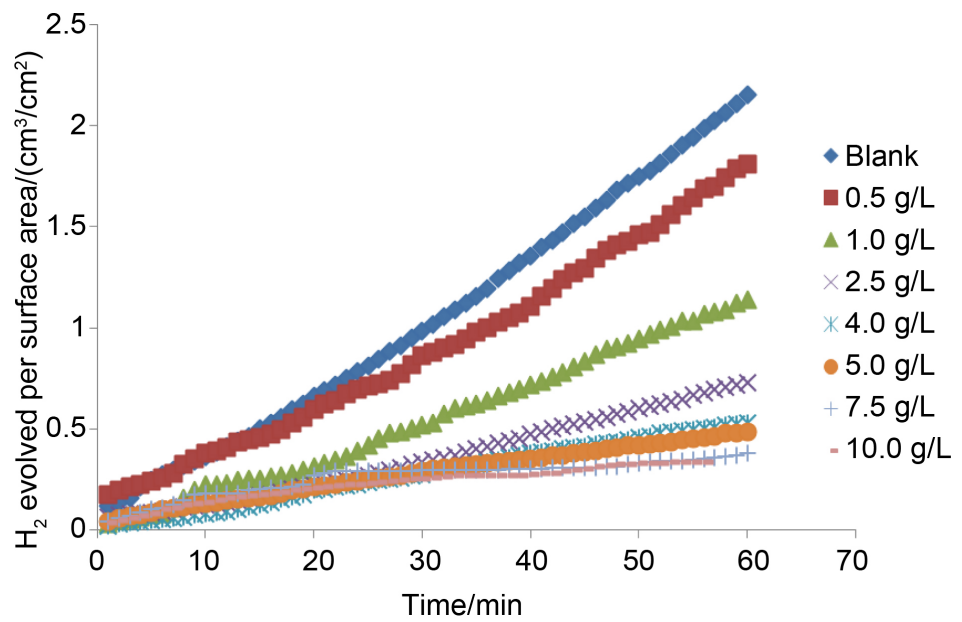

Figure 1. Variation of the volume of hydrogen evolved $\left(V_{H}\right)$ with time for mild steel in the presence and absence of different concentrations of EEVA in $5.0 \mathrm{M} \mathrm{H}_{2} \mathrm{SO}_{4}$ solution at $303 \mathrm{~K}$.

of plant extract. From the rate of hydrogen evolution, the inhibition efficiencies of different concentrations of flavonoids extract of Viscum album (FEVA), saponins extracts of Viscum album (SEVA), phytates extracts of Viscum album (PEVA) in $5.0 \mathrm{M} \mathrm{H}_{2} \mathrm{SO}_{4}$ solution at $303 \mathrm{~K}$ were determined and presented in Table 6. The results obtained indicate that inhibition efficiencies generally increased with increase in extracts concentration for all the extracts. The highest inhibition efficiency of $85.3 \%$ obtained at $5.0 \mathrm{~g} / \mathrm{L}$ SEVA, indicates that the dominant inhibitive effect of Viscum album may be attributed to SEVA while the lowest $\% I$ of $0.9 \%$ was obtained at $1.0 \mathrm{~g} / \mathrm{L}$ of FEVA. The Inhibition efficiency of EEVA was generally higher than that of SEVA, FEVA and PEVA at lower concentrations $(0.5-2.5 \mathrm{~g} / \mathrm{L})$, this suggests a synergistic interaction between the phytochemicals in Viscum album at low concentration. However, at higher concentrations of $5.0 \mathrm{~g} / \mathrm{L}$ the efficiency of PEVA (81.5\%) and SEVA (85.3\%) became more pronounced.

Comparison of the variation of inhibition efficiency with inhibitor concentration for EEVA, PEVA, SEVA and FEVA in $5.0 \mathrm{M} \mathrm{H}_{2} \mathrm{SO}_{4}$ at $303 \mathrm{~K}$ is presented in Figure 2. The order of the efficiency at low concentrations obey the following trend EEVA $>$ PEVA $>$ SEVA $>$ FEVA and at higher concentration the order was SEVA $>$ PEVA $>$ EEVA $>$ FEVA. This indicates synergism at lower concentration and the opposite at higher concentration.

The volume of hydrogen evolved during corrosion of mild steel in $5.0 \mathrm{M}$ $\mathrm{H}_{2} \mathrm{SO}_{4}$ containing $2.5 \mathrm{~g} / \mathrm{L}$ of PEVA at different temperatures is shown in Figure 3. From this figure, it is seen that the volume of hydrogen gas evolved increases with increase in temperature. Similar trends were obtained for FEVA and SEVA as shown in Figure 4 and Figure 5.

This is attributed to the increase in reaction rate which is known to increase with temperature. At elevated temperatures more of the reactant molecules gain enough energy required to overcome the energy barrier need to form products, 
Table 6. Rate of hydrogen evolution $\left(R_{H}\right)$ Surface Coverage $(\theta)$ and Inhibition Efficiency (\% I) of different concentrations of EEVA, SEVA, PEVA, FEVA in $5.0 \mathrm{M} \mathrm{H}_{2} \mathrm{SO}_{4}$ solution at $303^{\circ} \mathrm{C}$.

\begin{tabular}{|c|c|c|c|c|c|c|c|c|c|c|c|c|c|}
\hline \multirow{2}{*}{$\frac{\text { Conc }}{(\mathrm{g} / \mathrm{L})}$} & \multicolumn{5}{|c|}{ Corrosion Rate $/(\mathrm{cm} / \mathrm{min})$} & \multicolumn{4}{|c|}{$\Theta$} & \multicolumn{4}{|c|}{$\% I$} \\
\hline & Blank & EEVA & PEVA & SEVA & FEVA & EEVA & PEVA & SEVA & FEVA & EEVA & PEVA & SEVA & FEVA \\
\hline 0.5 & 0.0346 & 0.0278 & 0.0280 & 0.0320 & 0.0334 & 0.20 & 0.19 & 0.08 & 0.03 & 19.7 & 19.1 & 7.5 & 3.5 \\
\hline 1.0 & 0.0346 & 0.0191 & 0.0243 & 0.0246 & 60.0343 & 0.45 & 0.30 & 0.29 & 0.01 & 44.8 & 29.8 & 28.9 & 0.9 \\
\hline 2.5 & 0.0346 & 0.0118 & 0.0149 & 0.0130 & 0.0236 & 0.66 & 0.57 & 0.62 & 0.32 & 65.9 & 56.9 & 62.4 & 31.8 \\
\hline 5.0 & 0.0346 & 0.0073 & 0.0064 & 0.0051 & 10.0180 & 0.79 & 0.82 & 0.85 & 0.48 & 78.9 & 81.5 & 85.3 & 48.0 \\
\hline
\end{tabular}

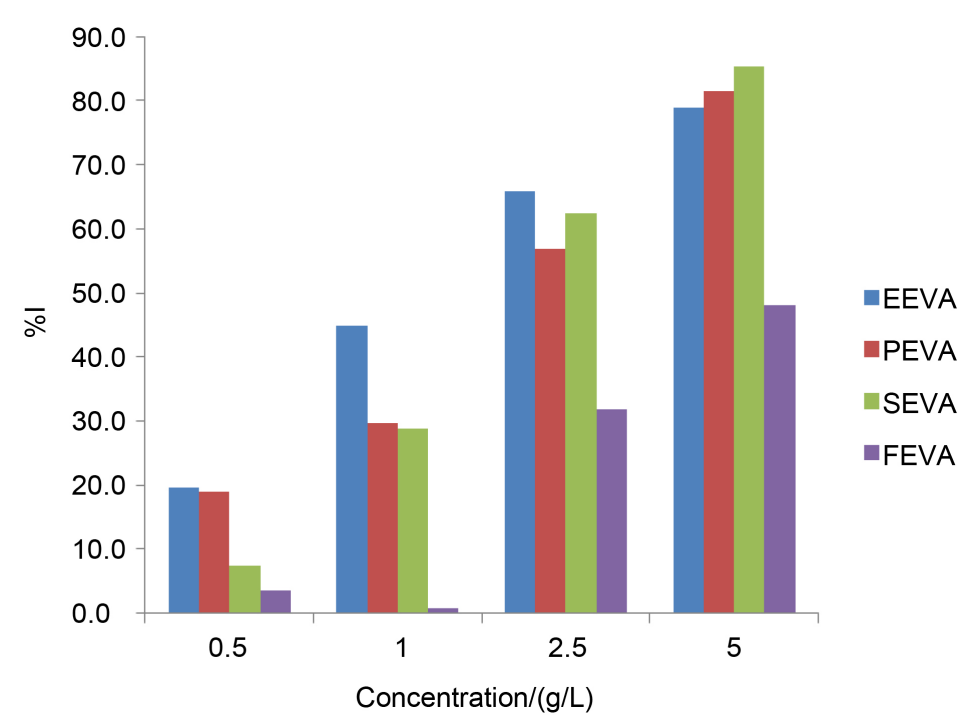

Figure 2. Comparison of the variation of inhibition efficiency with inhibitor concentration for EEVA, PEVA, SEVA and FEVA in $5.0 \mathrm{M} \mathrm{H}_{2} \mathrm{SO}_{4}$ at $303 \mathrm{~K}$.

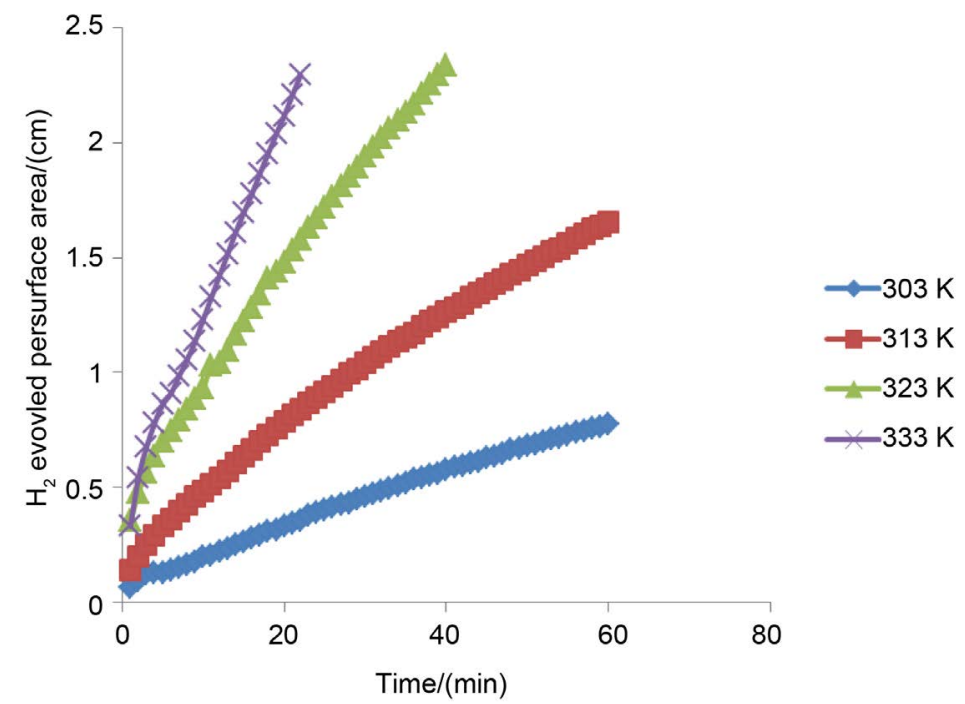

Figure 3. Varition of hydrogen gas evolved $\left(V_{H}\right)$ with time for mild steel in $5.0 \mathrm{M} \mathrm{H}_{2} \mathrm{SO}_{4}$ solution containing $2.5 \mathrm{~g} / \mathrm{L}$ of PEVA at different temperatures. 


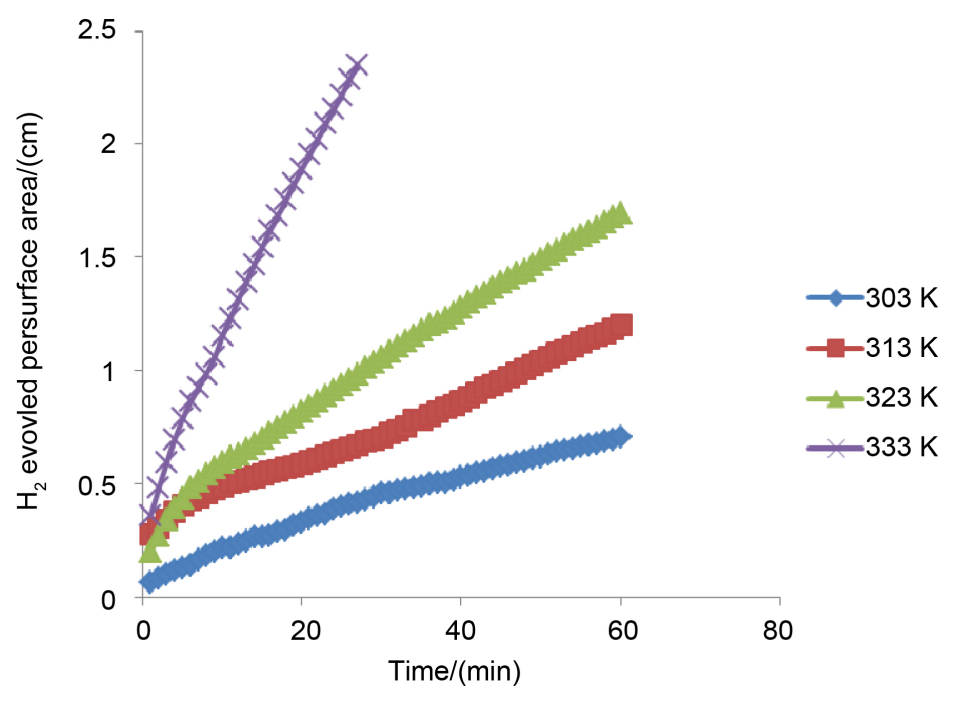

Figure 4. Varition of hydrogen gas evolved $\left(V_{H}\right)$ with time for mild steel in $5.0 \mathrm{M} \mathrm{H}_{2} \mathrm{SO}_{4}$ solution containing $2.5 \mathrm{~g} / \mathrm{L}$ of SEVA at different temperatures.

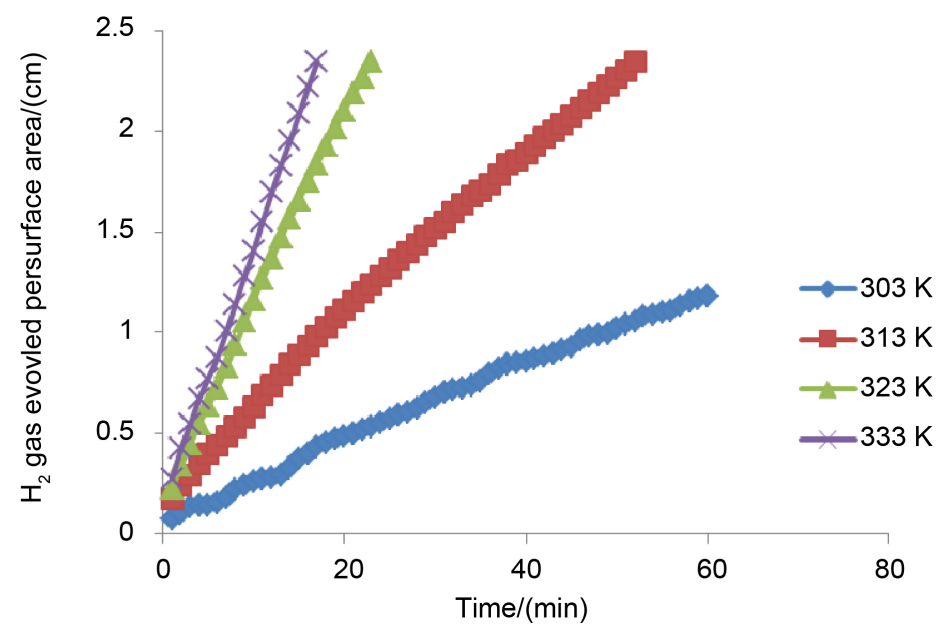

Figure 5. Varition of hydrogen gas evolved $\left(V_{H}\right)$ with time for mild steel in $5.0 \mathrm{M} \mathrm{H}_{2} \mathrm{SO}_{4}$ solution containing $2.5 \mathrm{~g} / \mathrm{L}$ of FEVA at different temperatures.

thus leading to the higher rates of hydrogen evolution. From the rate of hydrogen evolution, the inhibition efficiencies for mild steel in $5.0 \mathrm{M} \mathrm{H}_{2} \mathrm{SO}_{4}$ solution in the absence (blank) and presence of $2.5 \mathrm{~g} / \mathrm{L}$ of EEVA, FEVA, PEVA and SEVA at different temperatures were determined and presented in Table 7. The results obtained indicate that the inhibition efficiencies increase with an increase in temperature. The maximum $\%$ I, $91.8 \%$ was obtained at $333 \mathrm{~K}$ for $2.5 \mathrm{~g} / \mathrm{L}$ concentration of EEVA and the minimum $31.4 \%$ at $303 \mathrm{~K}$ for $2.5 \mathrm{~g} / \mathrm{L}$ concentration of FEVA. This suggests adsorption of the extracts via chemical interactions between the heterogeneous inhibitor molecules and the metal surface. The inhibitory effects observed for all the extracts can be attributed to the presence of hetero atoms in the molecular structure of the phytochemicals which provide good 
Table 7. The rate of hydrogen evolution $\left(R_{H}\right)$, Surface Coverage $(\theta)$ and Inhibition Efficiency $(\% I)$ for mild steel in $5 \mathrm{M} \mathrm{H}_{2} \mathrm{SO}_{4}$ solution in the absence and presence of $2.5 \mathrm{~g} / \mathrm{L}$ of EEVA, PEVA, SEVA and FEVA at different temperatures.

\begin{tabular}{|c|c|c|c|c|c|c|c|c|c|c|}
\hline \multirow{2}{*}{$\frac{\text { Temp }}{\mathrm{K}}$} & \multicolumn{2}{|l|}{$R_{H} /(\mathrm{cm} / \mathrm{min})$} & \multicolumn{4}{|c|}{$\boldsymbol{\theta}$} & \multicolumn{4}{|c|}{$\% I$} \\
\hline & Blank EEVA PEVA SEVA & FEVA & EEVA & PEVA & SEVA & FEVA & EEVA & PEVA & SEVA & FEVA \\
\hline 303 & $\begin{array}{llll}0.0346 & 0.0118 & 0.0149 & 0.013\end{array}$ & 0.0236 & 0.66 & 0.57 & 0.62 & 0.31 & 65.9 & 56.9 & 62.4 & 31.9 \\
\hline 313 & $\begin{array}{llll}0.1209 & 0.0135 & 0.0306 & 0.018\end{array}$ & 0.0518 & 0.87 & 0.66 & 0.72 & 0.32 & 87.4 & 66.2 & 71.9 & 32.4 \\
\hline 323 & $\begin{array}{llll}0.1797 & 0.0227 & 0.0607 & 0.029\end{array}$ & 0.1214 & 0.89 & 0.67 & 0.84 & 0.51 & 88.9 & 66.8 & 83.9 & 51.1 \\
\hline 333 & $\begin{array}{lllll}0.3297 & 0.0269 & 0.1094 & 0.093\end{array}$ & 0.1612 & 0.91 & 0.75 & 0.85 & 0.57 & 91.8 & 74.7 & 85.1 & 57.1 \\
\hline
\end{tabular}

adsorption sites unto the metal surface [20].

\subsection{Adsorption Consideration}

The observed corrosion inhibition of mild steel in $5.0 \mathrm{M} \mathrm{H}_{2} \mathrm{SO}_{4}$ solutions in the absence and presence of EEVA, PEVA, SEVA and FEVA can be explained by the adsorption of the components of the plant extract on the metal surface. The surface coverage values obtained from this study were applied to different adsorption isotherm equations. From the results, it was found that the experimental data fitted the Temkin adsorption isotherm shown in Figure 6 which may be formulated by Equation (3).

$$
f(\theta, x) \exp (-2 a \theta)=K_{a d s} C
$$

where, $f(\theta, x)$ is the configuration factor which depends upon the physical model and the assumption underlying the derivation of the isotherm, $c$ is the inhibitor concentration, $\theta$ is the degree of surface coverage and $K_{a d s}$ is the adsorption-desorption equilibrium constant, and " $a$ " is an interaction parameter. The calculated values of $K_{\text {ads }}$ and "a" are as shown in Table 8. The positive values of " $a$ " indicate attractive forces between adsorbed molecules while negative values indicate repulsive forces between the adsorbed molecules.

It can be seen in Table 8 that the value of " $a$ " is negative indicating that repulsion exists in the adsorption layer. It can also be observed from Table 8 that the correlation factors $\left(R^{2}\right)$ for the isotherms in the presence of EEVA and SEVA are 0.9804 and 0.9990 . This value is close to unity, signifying adherence to the principles underlying the derivation of the Temkin adsorption isotherm. It is generally known that $K_{a d s}$ denotes the strength between the adsorbate and adsorbent. Large values of $K_{a d s}$ imply more efficient adsorption and hence better inhibition efficiency [7]. In the present case, $K_{\text {ads }}$ values for PEVA and SEVA is higher than those of EEVA and FEVA. This implies that PEVA and SEVA are better adsorbed [7].

\subsection{Activation Parameters}

The rate of a chemical reaction increases with increase in temperature. Increase in temperature was found to increase the inhibition efficiencies of the plant 


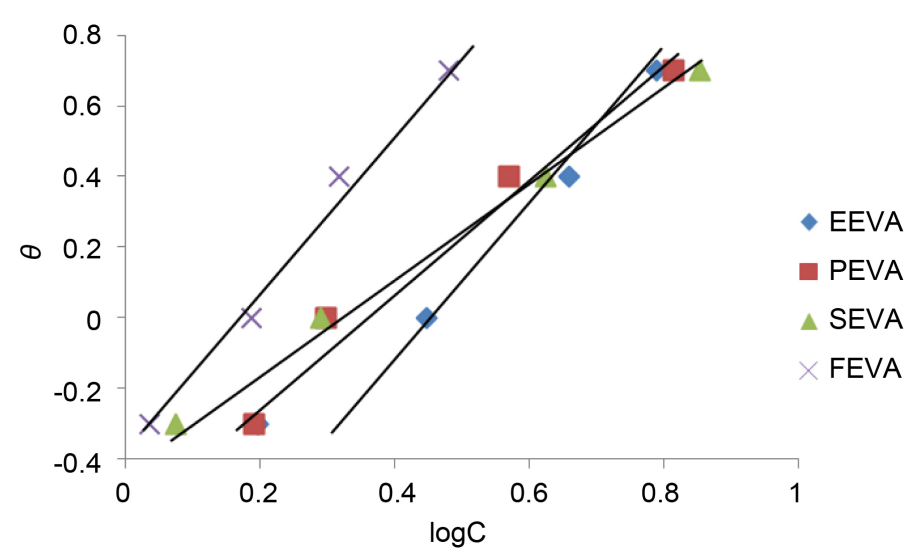

Figure 6. Temkin adsorption isotherm for mild steel in the presence of EEVA, PEVA, FEVA and SEVA at $303 \mathrm{~K}$.

Table 8. Temkin isotherm parameters for the adsorption of EEVA, SEVA, PEVA and FEVA on mild steel.

\begin{tabular}{ccccc}
\hline Parameter & EEVA & PEVA & SEVA & FEVA \\
\hline$R^{2}$ & 0.9804 & 0.9787 & 0.9990 & 0.9913 \\
$a$ & -0.8395 & -0.7740 & -0.6355 & -1.1553 \\
$K_{a d s}$ & 0.3197 & 0.4431 & 0.5126 & 0.4062 \\
\hline
\end{tabular}

extracts indicating chemical adsorption. In order to further support that chemisorption is proposed, the activation parameters for the mild steel in $5.0 \mathrm{M} \mathrm{H}_{2} \mathrm{SO}_{4}$ solutions in the absence and presence of the extracts from Viscum album were calculated using the Arrhenius equation and the transition state equation given by Equations (4) and (5), respectively.

$$
\begin{gathered}
K=A \exp \left(-\frac{E_{a}}{R T}\right) \\
K=\frac{R T}{N h} \exp \left(\frac{\Delta S^{0}}{R}\right) \exp \left(-\frac{\Delta H^{0}}{R T}\right)
\end{gathered}
$$

where, $R$ is the universal gas constant, $N$ is the Avogadro number, $h$ is the Plank's constant, $E_{a}$ is the activation energy, $T$ is the absolute temperature, and $\Delta H_{o}$ and $\Delta S_{o}$ are the standard enthalpy and entropy of activation, respectively. The values of $\mathrm{K}$ were taken to be equal to the rate of hydrogen evolution [18] [19]. The Arhenius plot of $\log K$ versus $1 / T$, for mild steel in $5.0 \mathrm{M} \mathrm{H}_{2} \mathrm{SO}_{4}$ solutions containing EEVA, PEVA, FEVA and SEVA shown in Figure 7 gave straight lines. The calculated activation energies obtained from the slope of the plots are listed in Table 9. The results showed that $E_{a}$ value in the presence of EEVA, PEVA, FEVA and SEVA is lower compared to the blank system. This behavior is an indication of chemical adsorption of the inhibitor on the surface of the metal [20] [21]. The lower $\mathrm{E}_{\mathrm{a}}$ value in the presence of the inhibitor indicates that the inhibitor will be effective at higher temperature and efficiencies will increase at low temperature. The enthalpy and the entropy of activation 


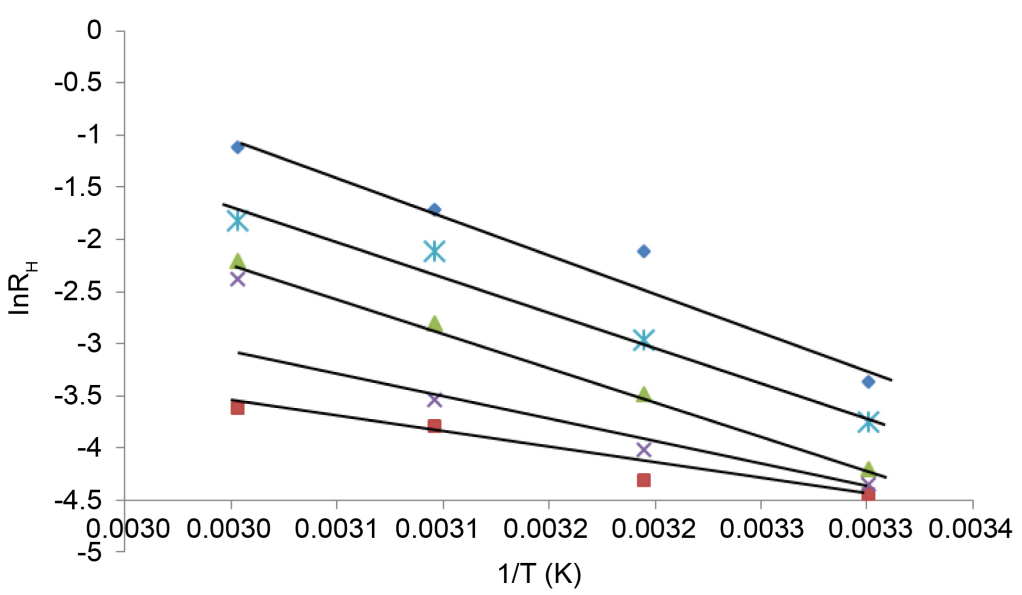

- Blank

-EEVA

$\triangle$ PEVA

$\times$ SEVA

KFEVA

Figure 7. Arrhenius plot for mild steel in the presence of EEVA, PEVA, FEVA and SEVA.

Table 9. Thermodynamic parameters for the corrosion of mild in the presence of EEVA, PEVA, FEVA and SEVA.

\begin{tabular}{cccccc}
\hline Parameters & Blank & EEVA & PEVA & SEVA & FEVA \\
\hline $\ln A$ & 20.29 & 5.45 & 18.01 & 16.50 & 18.43 \\
$E_{a} /(\mathrm{kJ} / \mathrm{mol})$ & 60.37 & 25.06 & 55.95 & 52.99 & 55.70 \\
$\Delta H /(\mathrm{kJ} / \mathrm{mol})$ & 57.73 & 22.42 & 53.31 & 50.35 & 53.06 \\
$\Delta S /(\mathrm{kJ} / \mathrm{mol})$ & -80.93 & -208.40 & -103.98 & -116.56 & -100.49 \\
\hline
\end{tabular}

values for the dissolution of mild steel in $5.0 \mathrm{M} \mathrm{H}_{2} \mathrm{SO}_{4}$ solutions obtained from linear transition state plots of $\log (K / T)$ data versus $1 / T$ shown in Figure 8 are presented in Table 9. The lower value for $\Delta H_{o}$ in the presence of the plant extract is indicative of lower protection efficiency observed for the system.

Generally, the positive value of $\Delta H_{o}$ obtained indicates an endothermic nature of the dissolution of mild steel in the presence of the inhibitors. The endothermic adsorption process can be attributable to chemisorption [22].

The $\Delta S_{o}$ value in the absence and presence of plant extract is negative. This implies that the activation complex in the rate determining step represents association rather than dissolution step, meaning that a decrease in disordering takes place on going from reactants to the activated complex. The negative value for entropy also indicates the non-spontaneous nature of the dissolution as a result of the addition of the inhibitors [23] [24] [25].

\section{Conclusions}

The following conclusions have been drawn from the results obtained:

1) The ethanol extracts from Viscum album exhibit inhibitive action on corrosion of mild steel in sulphuric acid. The inhibition efficiencies increased with increase in extracts concentration and increased with temperature.

2) Experimental data obtained in this study fits well into the Temkin adsorption isotherm equation. The corrosion inhibition is due to the chemical adsorption 


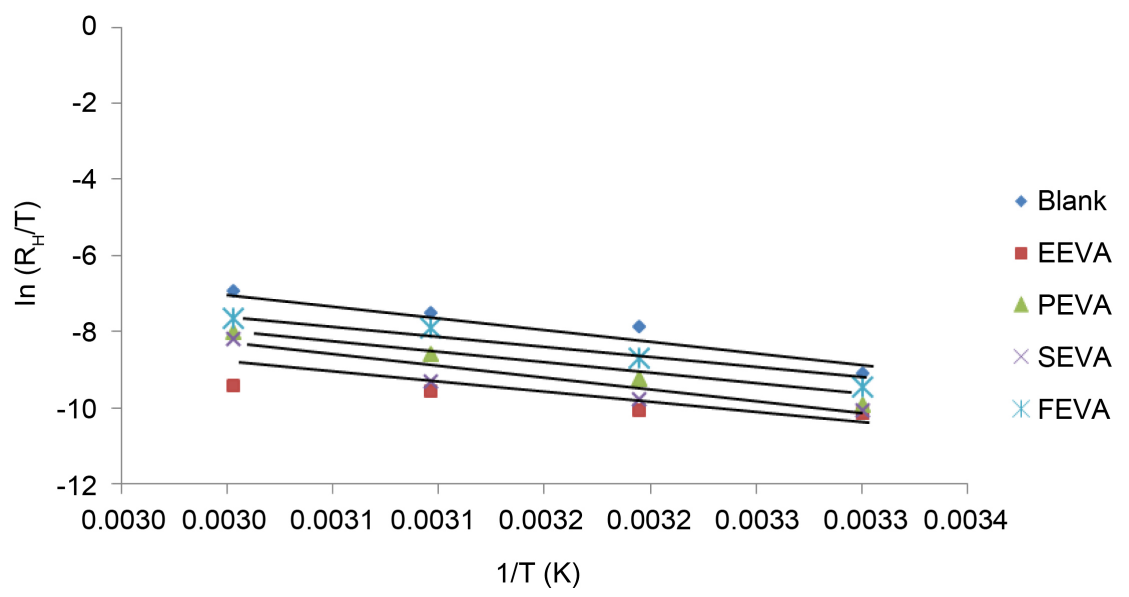

Figure 8. Transition state plots for mild steel in the presence of EEVA, PEVA, FEVA and SEVA.

of the inhibitor on the metal surface blocking its active sites by the phenomenon of chemical adsorption.

3) The order of the efficiency at low concentrations follows the trend, EEVA > PEVA $>$ SEVA $>$ FEVA while at higher concentration the trend was SEVA > PEVA $>$ EEVA $>$ FEVA.

4) The interaction between the isolated extracts is synergistic at lower inhibitor concentration and antagonistic at higher concentrations. The $K_{a d s}$ values for PEVA and SEVA are higher than those of EEVA and FEVA. This implies that PEVA and SEVA are more efficiently adsorbed on the mild steel surface.

5) The next phase of this research is to carry out molecular dynamic simulations of these appraised phytochemicals in order to clear certain aspects of the corrosion inhibition mechanism by the extracts.

\section{References}

[1] Ebenso, E.E., Eddy, N.O. and Odiogenyi, A.O. (2008) Corrosion Inhibitive Properties and Adsorption Behavior of Ethanol Extract of Piper guinensis as a Green Corrosion Inhibitor for Mild Steel in $\mathrm{H}_{2} \mathrm{SO}_{4}$. African Journal of Pure and Applied Chemistry, 2, 107-115.

[2] Ebenso, E.E. and Ekpe, U.J. (1996) Kinetic Study of Corrosion Inhibition of Mild Steel in $\mathrm{H}_{2} \mathrm{SO}_{4}$ Using Carica Papaya Leaves Extracts. West Africa Journal Biology and Apply Chemistry, 24, 143-195.

[3] Ebenso, E.E., Ekpe, U.J., Ibok, U.J., Umoren, S.A., Jackson, E., Abiola, O.K., Oforka, N.C. and Martinez, S. (2004) Corrosion Inhibition Studies of Some Plant Extracts on Aluminium in Acidic Medium. SAEST Transactions, 39, 117.

[4] Gunasekaran, G. and Chauhan L.R. (2004) Eco-Friendly Inhibitor for Corrosion of Mild Steel in Phosphoric Acid Medium. Electrochimica Acta, 49, 4387-4395. https://doi.org/10.1016/j.electacta.2004.04.030

[5] Okafor, P.C., Ebenso, E.E. and Ekpe, U.J. (2004) Inhibition of Acid Corrosion of Aluminum by Some Derivatives of Thiosemicarbazone. Bulletin of Chemical Society of Ethiopia, 18, 181-192. https://doi.org/10.4314/bcse.v18i2.61442

[6] Okafor, P.C., Ekpe, U.J., Ebenso, E.E., Oguzie, E.E., Umo, N.S. and Etor, A.R. (2006) 
Effect of Allium cepa and Allium sativum as Corrosion Inhibitors of Mild Steel in $\mathrm{HCl}$ Solutions. Transactions of the SAEST, 41, 82-87.

[7] Okafor, P.C., Ikpi, M.E., Uwah, I.E., Ebenso, Ekpe, U.J. and Umoren, S.A. (2008) Inhibitory Action of Phyllanthus amarus Extracts on the Corrosion of Mild Steel in Acidic Media. Corrosion Science, 50, 2310-2317.

https://doi.org/10.1016/j.corsci.2008.05.009

[8] Okafor, P.C., Ebiekpe, V.E., Azike, C.F., Egbung, G.E., Brisibe, E.A. and Ebenso, E.E. (2012) Inhibitory Action of Artenisia annua Extracts Artemisinin on the Corrosion of Mild Steel in $\mathrm{H}_{2} \mathrm{SO}_{4}$ Solutions. International Journal of Corrosion, 2012, 8. https://doi.org/10.1155/2012/768729

[9] El-Etre, A.Y., (2003) Inhibition of Aluminium Corrosion Using Opuntia Extracts. Corrosion Science, 45, 2485-2495. https://doi.org/10.1016/S0010-938X(03)00066-0

[10] Abdel-Gaber, A.M., Abdel-El-Nabey, B.A., Sidahmed I.M., El-Zayady A.M. and Saadawy, M. (2006) Inhibition Action of Some Plant Extracts on the Corrosion of Steel in Acidic Media. Corrosion Science, 48, 2765-2779.

https://doi.org/10.1016/j.corsci.2005.09.017

[11] Umoren, S.A., Obot, I.B., Ebenso, E.E., Okafor, P.C., Ogbobe, O. and Oguzie, E.E. (2006) Gum Arabic as a Potential Corrosion Inhibitor for Aluminium in Alkaline Medium and Its Adsorption Characteristics. Anti-Corrosion Methods and Materials, 53, 277-282. https://doi.org/10.1108/00035590610692554

[12] Duke, J.A. (1985) Mistletoe. Handbook of Medicinal Herbs, CRC Press, Florida, 512-513.

[13] Pamplona-Roger, G.H. (1999) Medicinal Plants Encyclopedia of Medicinal Plants. Safeliz Publication, Spain, 5-247.

[14] Blumenthal, M., Busse, W.R. and Goldberg, A. (1998) Therapeutic Guide to Herbal Medicine. The Complete German Commission E. Monographs, 171, 2-3

[15] Gray, A.M. and Flatt, P.R. (1999) Insulin-Secreting Activities of the Traditional Antidiabetic Plant Viscum album. Journal of Endocrinology, 160, 409-414. https://doi.org/10.1677/joe.0.1600409

[16] Harbone, J.B. (1973) Phytochemical Methods. Chapman and Hill, London.

[17] Trease, G.E. and Evans, W.C. (1996) A Textbook of Pharmacology. Baillier Tidally, London.

[18] Okafor, P.C. and Ebenso, E.E. (2007) Inhibitive Action of Carica Papaya Extracts on the Corrosion of Mild Steel in Acidic Media and Their Adsorption Characteristics. Pigment and Resin Technology, 36, 134-140. https://doi.org/10.1108/03699420710748992

[19] Oguzie, E.E., Onuoha, G.N. and Onuchukwu, A.I. (2005) The Inhibition of Aluminium Corrosion in Potassium Hydroxide by Congo Red Dye, and Synergistic Action with Halideions. Anti-Corrosion Methods and Materials, 52, 293-298. https://doi.org/10.1108/00035590510615794

[20] Ikeuba, A.I., Okafor, P.C., Ekpe, U.J. and Ebenso, E.E. (2013) Alkaloid and Non-Alkaloid Ethanolic Extracts from Seeds of Garcinia kola as Green Corrosion Inhibitor of Mild Steel in $\mathrm{H}_{2} \mathrm{SO}_{4}$ Solutions. International Journal of Electrochemical Science, 8, 7455-7467.

[21] Ikpi, M.E., Udoh, I.I., Okafor, P.C., Ekpe, U.J. and Ebenso, E.E. (2012) Corrosion Inhibition and Adsorption Behaviour of Extracts from Piper Guinensis on Mild Steel Corrosion in Acidic Media. International Journal of Electrochemical Science, 7, 12193-12206. 
[22] Uwah, I.E. Okafor, P.C. and Ebiekpe, V.E. (2010) Inhibitive Action of Ethanol Extracts from Nauclea latifolia on the Corrosion of Mild Steel in $\mathrm{H}_{2} \mathrm{SO}_{4}$ Solutions and Their Adsorption Characteristics. Arabian Journal of Chemistry, 6, 285-293. https://doi.org/10.1016/j.arabjc.2010.10.008

[23] Abd El Rehim, S.S., Ibrahim, M.A.M. and Khaled, K.F. (2001) The Inhibition of 4-(2-amino-5-methylphenylazo) Antipyrine on Corrosion of Mild Steel in $\mathrm{HCl}$ Solution. Material Chemistry and Physics, 70, 268-273.

https://doi.org/10.1016/S0254-0584(00)00462-4

[24] Ekpe, U.J., Okafor, P.C., Ebenso, E.E., Offiong, O.E. and Ita, I.B. (2001) Mutual Effect of TSC Derivatives on the Acidic Corrosion of Aluminium. Bulletin of Electrochemistry, 17, 131-135.

[25] Ikeuba, A.I., Ita, B.I., Okafor, P.C., Ugi, B.U. and Kporokpo, E.B. (2015) Green Corrosion Inhibitors for Mild Steel in $\mathrm{H}_{2} \mathrm{SO}_{4}$ Solution: Comparative Study of Flavonoids Extracted from Gongronema atifoliunm with Crude the Extract. Protection of Metals and Physical Chemistry of Surfaces, 51, 1043-1049.

https://doi.org/10.1134/S2070205115060118 